\title{
ATRIBUTOS FÍSICOS, QUÍMICOS E BIOLÓGICOS DE SOLO DE CERRADO SOB DIFERENTES SISTEMAS DE USO E MANEJO(1)
}

\author{
Marco Aurélio Carbone Carneiro(2), Edicarlos Damacena de $\operatorname{Souza}^{(3)}$, \\ Edésio Fialho dos Reis ${ }^{(2)}$, Hamilton Seron Pereira ${ }^{(2)} \&$ Watson
}

Rogério de Azevedo ${ }^{(4)}$

\begin{abstract}
RESUMO
À medida que o conhecimento do sistema plantio direto se amplia, verifica-se que o uso de indicadores químicos isolados não permite melhor caracterização dos solos, sendo necessário utilizar um conjunto de indicadores da qualidade do solo com a entrada de outros atributos, entre eles os físicos e os biológicos. Objetivouse avaliar os efeitos de sistemas de manejo e uso do solo nos atributos físicos, químicos e biológicos de um Latossolo Vermelho distrófico e um Neossolo Quartzarênico órtico sob Cerrado, no entorno do Parque Nacional das Emas. Os aspectos avaliados no Latossolo foram: Cerrado nativo, pastagem, milheto em preparo convencional, nabo forrageiro em plantio direto e sorgo em plantio direto. No Neossolo: Cerrado nativo, pastagem nativa, integração agricultura-pecuária, pastagem cultivada, plantio direto com soja no verão e plantio direto com milho no verão. As amostras de solo foram coletadas na profundidade de 0 a $10 \mathrm{~cm}$. $O$ delineamento experimental foi o inteiramente casualizado, com cinco parcelas de $150 \mathrm{~m}^{2}$, sendo coletadas 10 subamostras aleatórias. As análises químicas, físicas e biológicas foram realizadas no Laboratório de Solos da UFG/CJ. Os manejos promoveram alterações na densidade do solo, volume total de poros, macroporos e resistência do solo à penetração no Neossolo e no Latossolo, excetuando-se neste o volume total de poros. Houve pequena variação nos atributos químicos nos dois solos, com o Cerrado apresentando maior acidez potencial e menor teor de cátions trocáveis e $\mathrm{P}$. Os atributos biológicos do solo foram alterados pelos sistemas de manejo, sendo mais prejudicados em sistemas com maior revolvimento do solo. A análise canônica dos dados demonstrou que os atributos físicos foram os de menor
\end{abstract}

\footnotetext{
(1) Trabalho financiado pelo CNPq processo 476302/2003-0. Recebido para publicação em novembro de 2007 e aprovado em novembro de 2008

(2) Professor Adjunto da Universidade Federal de Goiás - UFG. Campus de Jataí, BR 364, km 192, Zona Rural, CEP $75800-000$ Jataí (GO). E-mails: carbonecarneiro@pq.cnpq.br; edesio7@brturbo.com.br; hseron@uol.com.br

(3) Pos-Doutorando do Programa de Pós-Graduação em Agronomia, UFG. E-mail: edicarlos@pq.cnpq.br

(4) Professor do Instituto Federal de Educação, Ciência e Tecnologia Goiano - Campus de Rio Verde. Caixa Postal 66, CEP 75901 970 Rio Verde (GO). E-mail: azevedowr@yahoo.com.br
} 


\begin{abstract}
importância por apresentar maior coeficiente de ponderação nas variáveis canônicas. Os atributos do solo, isoladamente, pouco contribuíram para a avaliação da qualidade do solo: no entanto, quando se usou a análise multivariada, subsidiaram a constatação dos manejos do solo mais sustentáveis.
\end{abstract}

Termos de indexação: análise multivariada, C fração leve, plantio direto.

\title{
SUMMARY: PHYSICAL, CHEMICAL AND BIOLOGICAL PROPERTIES OF CERRADO SOIL UNDER DIFFERENT LAND USE AND TILLAGE SYSTEMS
}

\begin{abstract}
As knowledge on no-till system expands, it has become quite clear that separate chemical indicators cannot provide a detailed soil characterization. The objective of this study was to evaluate the effects of tillage systems and soil use in the physical, chemical and biological properties of a clayey dystrophic Red Latosol - Oxisol and a sandy Neosol - Entisol. The treatments for the Oxisol consisted of: native savanna, pasture, conventional tillage, no-tillage with turnip and with forage sorghum as cover crop. For the Entisol: native savanna, native pasture, integrated crop-livestock, cultivated pasture, no-tillage with soybean and corn in the summer. Soil samples were collected from a depth of 0-10 cm, in a clayey dystrophic Red Latosol - Oxisol and a sandy Neosol - Entisol in a savanna ecosystem, near the Parque Nacional das Emas. Treatments were arranged in a completely randomized design, in 5 plots of $150 \mathrm{~m}^{2}$, where $10 \mathrm{sub}$-samples were collected randomly. Chemical, physical and biological analyses were carried out at a soil laboratory. In the Entisol, tillage influenced the soil density, total pore volume, macroporosity and penetration resistance. In the Oxisol, tillage induced variations in soil bulk density, macroporosity and penetration resistance. Small variations in chemical properties were observed in both soils, with higher potential acidity and lower exchangeable cation and phosphorus concentrations. The soil biological properties were influenced by tillage, and were most affected in systems with more anthropic action. In the canonical data analysis the greater weighting coefficient of the physical properties in the canonic variables demonstrated that these were the least important. The contribution of the separate soil properties to evaluate soil quality was minor, but the most sustainable management systems could be defined by multivariate analysis.
\end{abstract}

Index terms: multivariate analysis, light carbon fraction, soil quality.

\section{INTRODUÇÃO}

A adoção de sistemas conservacionistas de manejo do solo como plantio direto tem-se apresentado como uma alternativa para contribuir com a sustentabilidade econômica e ambiental do agroecossistema (Silva et al., 2000). A integração agricultura-pecuária em conjunto com o plantio direto merece destaque nesse contexto (Kluthcouski et al., 2003), principalmente em solos de extrema fragilidade, como os arenosos, visto que possibilita a manutenção e, ou, melhoria nos atributos físicos, químicos e biológicos do solo.

A qualidade desses atributos propicia condições adequadas para o crescimento e o desenvolvimento das plantas e para a manutenção da diversidade de organismos que habitam o solo (Doran \& Parkin, 1994). No solo, existem diversas inter-relações entre os atributos físicos, químicos e biológicos que controlam os processos e os aspectos relacionados à sua variação no tempo e no espaço. Assim, qualquer alteração no solo pode alterar diretamente sua estrutura e sua atividade biológica e, consequentemente, sua fertilidade, com reflexos nos agroecossistemas (Brookes, 1995), podendo promover prejuízos à qualidade do solo e à produtividade das culturas. Diante disso, a variação desses atributos, determinada pelo manejo e uso do solo, e sua avaliação são importantes para o melhor manejo visando à sustentabilidade do sistema.

Essa avaliação é complexa e deve ser realizada em função de um conjunto de indicadores específicos (atributos) e suas inter-relações, já que se tem verificado que indicadores isolados não são suficientes para explicar a perda ou o ganho potencial dos cultivos de determinado solo. Observa-se que, com o aumento do conhecimento dos sistemas conservacionistas, verifica-se a necessidade da utilização de um conjunto de indicadores e, eventualmente, a inclusão deles em um modelo de avaliação da qualidade do solo (Nicolodi, 2006).

Atualmente são conhecidos efeitos isolados de diferentes manejos e uso do solo nos atributos físicos, químicos e biológicos. No entanto, há a necessidade de avaliar esses atributos em conjunto, principalmente em solos do bioma Cerrado. Assim, a utilização de 
análise multivariada dos dados poderá indicar diferenças e estabelecer as relações entre os tratamentos e os atributos avaliados, tornando-se uma ferramenta importante na análise das informações obtidas (Cruz-Castilho et al., 1994).

O objetivo deste estudo foi avaliar os efeitos de sistemas de manejos e usos do solo nos atributos físicos, químicos e biológicos de um Neossolo Quartzarênico órtico e um Latossolo Vermelho distrófico de Cerrado, bem como estabelecer inter-relações com a qualidade do solo.

\section{MATERIAL E MÉTODOS}

Este estudo foi realizado em janeiro de $2004 \mathrm{em}$ duas localidades no entorno do Parque Nacional das Emas. A primeira área está localizada próximo à nascente do rio Sucuriú $\left(18^{\circ} 22^{\prime} \mathrm{S} 52^{\circ} 47^{\prime} \mathrm{W}\right.$ e altitude de $850 \mathrm{~m}$ ) no município de Costa Rica (MS). O solo foi classificado como Latossolo Vermelho distrófico, apresentando granulometria de 621, $252 \mathrm{e}$ $127 \mathrm{~g} \mathrm{~kg}^{-1}$ de argila, silte e areia, respectivamente, com relevo suave ondulado. A segunda área está localizada no município de Mineiros (GO), nas imediações da nascente do rio Araguaia (18 ${ }^{\circ} 53^{\prime} \mathrm{S}$ $53^{\circ} 06 \mathrm{~W}$ e altitude de $800 \mathrm{~m}$ ). Nesta área, o solo foi classificado como Neossolo Quartzarênico órtico, apresentando granulometria de 38, 42 e $920 \mathrm{~g} \mathrm{~kg}^{-1} \mathrm{de}$ argila, silte e areia, respectivamente, com relevo ondulado. A região de ambos os solos é caracterizada, segundo Köppen, por clima tropical chuvoso (Aw), apresentando temperatura média anual de 18 a $32{ }^{\circ} \mathrm{C}$ e precipitação pluvial média anual em torno de $1.700 \mathrm{~mm}$. No quadro 1 é apresentada a descrição detalhada de cada experimento, com o respectivo histórico das áreas nos dois solos estudados.

O delineamento utilizado foi o inteiramente casualizado com cinco parcelas de $150 \mathrm{~m}^{2}$ em cada sistema de manejo e uso do solo, com distância de $500 \mathrm{~m}$ entre elas. Para as avaliações químicas e biológicas, retiraram-se 10 subamostras aleatórias dentro de cada parcela, perfazendo uma amostra composta, na profundidade de 0 a $10 \mathrm{~cm}$. Já para as análises físicas, foram coletadas 10 subamostras indeformadas, aleatoriamente, dentro de cada parcela, nas profundidades de 0 a 5 e 5 a $10 \mathrm{~cm}$ (utilizando a média de 0 a $10 \mathrm{~cm}$ ), com auxílio de anéis com volume conhecido, totalizando 10 repetições por parcela, sendo essas imediatamente acondicionadas em papel alumínio e sacos plásticos e, posteriormente, colocadas em caixas, para evitar a perda da estrutura do solo. Todas as amostras foram armazenadas em caixas térmicas e levadas imediatamente para o Laboratório de Solos da Universidade Federal de Goiás/Campus de Jataí. Parte das amostras foi seca ao ar, até massa constante, e passada em peneira de $2 \mathrm{~mm}$ de abertura, para determinação dos atributos químicos. Parte das amostras foi peneirada, imediatamente após a coleta, e armazenada em refrigeração a $4^{\circ} \mathrm{C}$ até a realização das análises biológicas (Quadro 2).

Quadro 1. Histórico e descrição das áreas experimentais (tratamentos) estudadas no Neossolo Quartzarênico órtico e Latossolo Vermelho distrófico

\begin{tabular}{|c|c|}
\hline Sistema de uso e manejo do solo & Descrição \\
\hline & Neossolo Quartzarênico órtico \\
\hline Cerrado nativo & $\begin{array}{l}\text { Área de mata fechada apresentando serapilheira espessa e utilizada como referência, já que não } \\
\text { houve intervenção antrópica. Área total de } 46 \text { ha. }\end{array}$ \\
\hline Pastagem nativa & $\begin{array}{l}\text { Área de Cerrado (campo sujo), apresentando vegetação graminoide e arbustivas, que foi } \\
\text { utilizada pela exploração pecuária desde 1993, apresentando erosões laminares e em sulcos. A } \\
\text { partir de } 2001 \text { a área foi fechada, sem animais, e está em processo de reabilitação natural. Área } \\
\text { total de } 40 \text { ha. }\end{array}$ \\
\hline Integração agricultura-pecuária & $\begin{array}{l}\text { Em agosto de } 2001 \text {, aplicaram-se } 2 \mathrm{Mg} \mathrm{ha}^{-1} \text { de calcário dolomítico }(\mathrm{CaO}: 23 \% \text {; } \mathrm{MgO}: 18 \% \text { e PRNT: } \\
50 \%), 400 \mathrm{Mg} \mathrm{ha} \text { de fosfato de Gafsa }\left(29 \% \text { de } \mathrm{P}_{2} \mathrm{O}_{5} \text { total com } 15 \% \text { de } \mathrm{P}_{2} \mathrm{O}_{5} \text { solúvel em citrato }\right. \\
\text { neutro de amônio). Nas primeiras chuvas, semeou-se milheto, que foi dessecado em novembro } \\
\text { para a semeadura de soja em } \mathrm{PD} \text { (cultivar Monarca), aplicando } 250 \mathrm{~kg} \mathrm{ha}^{-1} \text { de NPK da fórmula } \\
\text { 06- } 20-12+30 \% \text { de } \mathrm{Zn} \text {. Após a colheita da soja, foi semeado milho conjuntamente com } \\
\text { Brachiaria decumbens (plantio safrinha), sendo adubado com } 124 \mathrm{~kg} \mathrm{ha}^{-1} \text { de NPK da fórmula } \\
\text { 02-24-12 e cobertura com } 163 \mathrm{~kg} \mathrm{ha}^{-1} \text { de } 30-00-10 . \text { Após a colheita do milho, vedou-se a área para } \\
\text { o crescimento da braquiária, que recebe } 20 \mathrm{~kg} \mathrm{ha}^{-1} \text { ano }^{-1} \text { de N, e posteriormente introduziu-se gado } \\
\text { de corte. Área total de } 48 \text { ha. }\end{array}$ \\
\hline Pastagem cultivada & $\begin{array}{l}\text { Pastagem com Brachiaria decumbens desde 1993, com uma única aplicação de } 1,5 \mathrm{Mg} \mathrm{ha}^{-1} \text { de } \\
\text { calcário dolomítico em superfície e animais (gado) em pastejo contínuo. Área total de } 42 \text { ha. }\end{array}$ \\
\hline Soja em plantio direto & $\begin{array}{l}\text { De } 1993 \text { até } 2001 \text {, a área foi ocupada por pastagem. A braquiária foi dessecada aplicando-se } \\
\text { 1,5 } \mathrm{Mg}^{-1} \text { de calcário dolomítico em superfície. Semeou-se soja em PD (cultivar EMGOPA } 313 \text { ), } \\
\text { inoculada com estipes de Rhizobium CPAC } 15 \text { e CPAC } 7 \text {, e aplicação de } 550 \mathrm{~kg}^{-1} \text { de NPK na } \\
\text { fórmula 2-20-18. Na maturação da soja, foram semeadas a lanço sementes de Brachiaria } \\
\text { decumbens; após a colheita da soja, a área foi fechada para o desenvolvimento da pastagem } \\
\text { sendo, portanto, utilizado soja na safra em sistema de plantio direto. Área total de } 32 \text { ha. }\end{array}$ \\
\hline
\end{tabular}




\section{Quadro 1. Continuação}

\begin{tabular}{|c|c|}
\hline Sistema de uso e manejo do solo & Descrição \\
\hline \multirow[t]{2}{*}{ Milho em plantio direto } & $\begin{array}{l}\text { Neossolo Quartzarênico órtico } \\
\text { De } 1993 \text { até 2001, a área foi ocupada por pastagem. A braquiária foi dessecada e aplicados } 2 \mathrm{Mg} \mathrm{ha}^{-1} \\
\text { de calcário dolomítico em superfície. Semeou-se milho (cultivar Dekalb } 350 \text { ) conjuntamente } \\
\text { com Brachiaria decumbens, aplicando-se } 451 \mathrm{~kg} \mathrm{ha}^{-1} \text { de NPK na fórmula 08-20-18+0,3\% de } \mathrm{Zn} \text {. } \\
\text { Após a colheita do milho, a espécie Brachiaria decumbens estabelecida foi dessecada novamente } \\
\text { no próximo ano agrícola para semeadura de milho, portanto em sistema plantio direto sempre } \\
\text { utilizando milho na safra. Área total de } 38 \text { ha. }\end{array}$ \\
\hline & Latossolo Vermelho distrófico \\
\hline Cerrado nativo & Área de Cerrado nativo com serapilheira densa, utilizado como referência. Área total de 57 ha. \\
\hline Pastagem cultivada & $\begin{array}{l}\text { Em } 2001 \text { foi aplicado } 1 \mathrm{Mg} \mathrm{ha}^{-1} \text { de calcário dolomítico incorporado utilizando grade. Semeou-se } \\
\text { milho (cultivar precoce NK Fort) com aplicação de } 300 \mathrm{~kg}^{-1} \text { de NPK na fórmula } 08-20-20+ \\
0,3 \% \text { de } \mathrm{Zn} \text { e cobertura de } 372 \mathrm{~kg} \mathrm{ha}^{-1} \text { na fórmula } 25-00-15 \text {. Após a colheita do milho semeou-se } \\
\text { Brachiaria decumbens, com aplicação de } 80 \mathrm{~kg} \mathrm{ha}^{-1} \text { de } \mathrm{KCl} \text {. Atualmente vem sendo realizada } \\
\text { adubação de cobertura de } 80 \mathrm{~kg} \mathrm{ha}^{-1} \text { de } \mathrm{N} \text {. Sequência: milho/braquiária. Presença de animais } \\
\text { (gado) em pastejo contínuo. Área total de } 38 \mathrm{ha} \text {. }\end{array}$ \\
\hline Milheto em preparo convencional & $\begin{array}{l}\text { Em } 2001 \text { foi realizada a aplicação de } 1 \mathrm{Mg} \mathrm{ha}^{-1} \text { de calcário dolomítico (CaO: } 22 \% \text {; } \mathrm{MgO}: 18 \% \\
\text { PRNT: } 85 \% \text { e semeadura do milho (cultivar precoce NK Fort) aplicando-se } 454 \mathrm{~kg} \mathrm{ha}^{-1} \mathrm{de} \mathrm{NPK} \\
\text { na fórmula 08-20-20 + 0,3\% } \mathrm{Zn} \text { e como cobertura aplicou-se uma média de } 340 \mathrm{~kg} \mathrm{ha}^{-1} \text { de NPK } \\
\text { na fórmula } 25-00-15 \text {. Após a colheita do milho, semeou-se milheto na safrinha para palhada. Em } \\
2002 \text {, semeou-se soja (cultivar Pintada), aplicando-se } 250 \mathrm{~kg} \mathrm{ha}^{-1} \text { de NPK na fórmula 00-18-18. } \\
\text { Após a colheita da soja, semeou-se milheto na safrinha em sistema de plantio convencional. Após } \\
\text { sequência na área foi a de milho/milheto/soja/milheto. Área total de } 40 \text { ha. }\end{array}$ \\
\hline Nabo em plantio direto & $\begin{array}{l}\text { Em } 2001 \text { foi realizada a aplicação de } 1 \mathrm{Mg} \mathrm{ha}^{-1} \text { de calcário dolomítico (CaO: } 22 \% \text {; } \mathrm{MgO}: 18 \% \text {; } \\
\text { PRNT: } 85 \% \text { e semeadura de soja (cultivar Monsoy } 8400 \text { ), aplicando-se } 374 \mathrm{~kg} \text { ha }{ }^{-1} \text { de NPK na } \\
\text { fórmula 00-18-18. Após a colheita da soja em PD, semeou-se nabo forrageiro na safrinha. Em } \\
2002 \text { semeou-se milho (cultivar Pioneer } 3027 \text { ), aplicando-se } 389 \mathrm{~kg} \mathrm{ha}^{-1} \text { de NPK na fórmula 08- } \\
20-20 \text { e nabo na safrinha, e assim sucessivamente, sempre em sistema de plantio direto. A } \\
\text { sequência desde } 2001 \text { foi: soja/nabo/milho/nabo. Área total de } 42 \text { ha. }\end{array}$ \\
\hline Sorgo em plantio direto & $\begin{array}{l}\text { Em } 2001 \text { foi realizada a aplicação de } \mathrm{Mg} \mathrm{ha}^{-1} \text { de calcário dolomítico e plantio direto da soja } \\
\text { (cultivar Monsoy } 8400 \text { ) na safra, com adubação de } 221 \mathrm{~kg} \mathrm{ha}^{-1} \text { de NPK na fórmula } 0-18-18 \text {. Em } \\
2002 \text { semeou-se milho (cultivar DINA } 657 \text { semiprecoce), com aplicação de } 307 \mathrm{~kg} \text { ha }{ }^{-1} \text { de NPK na } \\
\text { fórmula 00-20-20 + 0,3\% de Zn e cobertura de } 377 \mathrm{~kg} \mathrm{ha}^{-1} \text { de } 25-00-15 \text {. Após a colheita do milho, } \\
\text { semeou-se sorgo (Agroceres - AG } 2501 \mathrm{C} \text { ), com aplicação de } 200 \mathrm{~kg} \mathrm{ha}^{-1} \text { de NPK na fórmula 08-20- } \\
20 \text {. A sequência desde } 2001 \text { foi: soja/milho/sorgo/soja. Área total de } 39 \text { ha. }\end{array}$ \\
\hline
\end{tabular}

Quadro 2. Atributos físicos, químicos e biológicos do solo e métodos utilizados para sua determinação

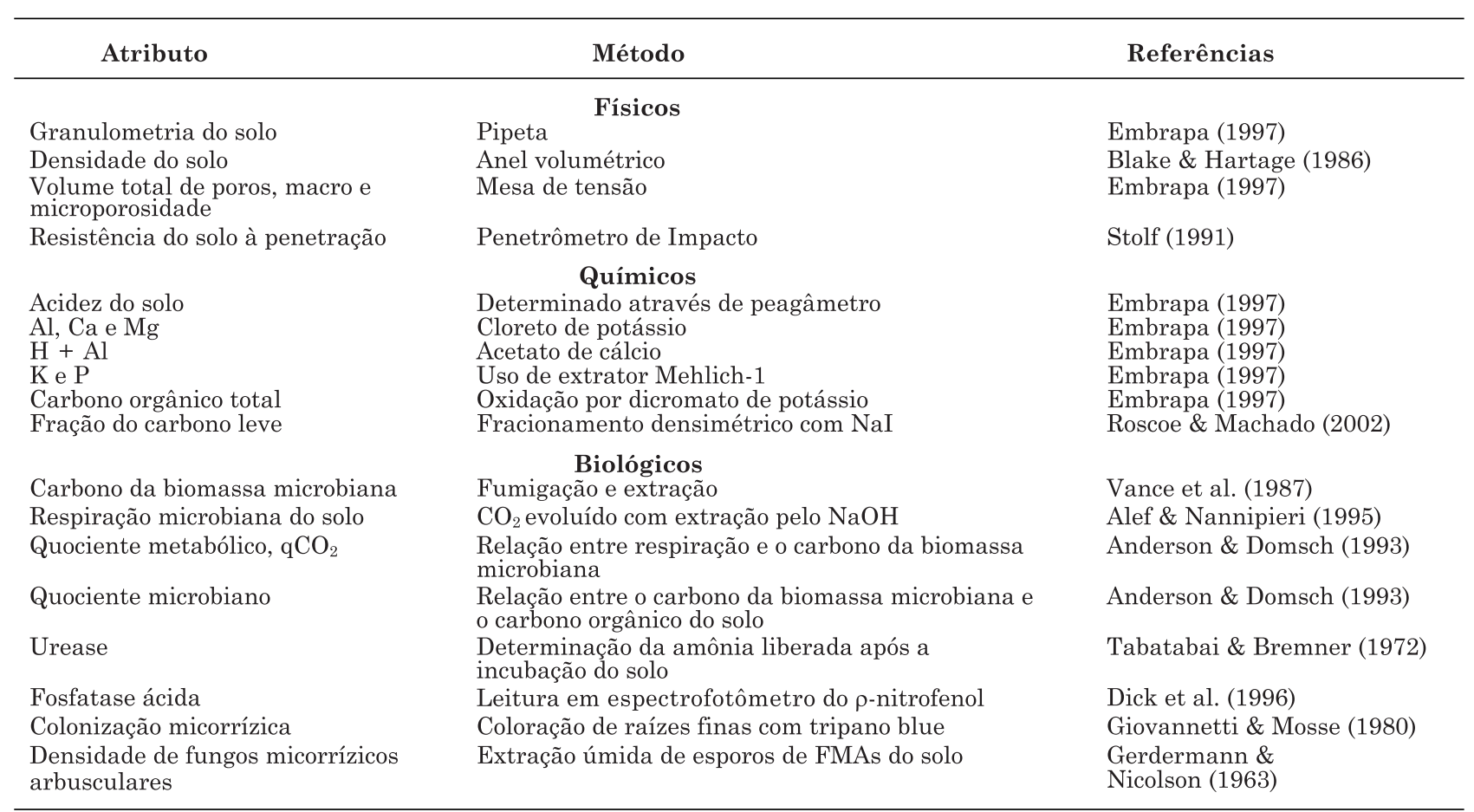


Os resultados foram submetidos à análise de variância e a teste de médias, utilizando o teste de Tukey a $5 \%$ (SAEG). Como análise complementar, foi utilizada a técnica multivariada por meio da análise canônica, envolvendo todas as variáveis em estudo, a partir da qual foi reduzido o conjunto de dados em combinações lineares, gerando os escores das duas primeiras variáveis canônicas que explicam mais de $80 \%$ da variação total, conforme recomendado por Cruz \& Regazzi (1994). Esses escores são projetados em gráficos bidimensionais. Além dessa técnica, foi ainda utilizado o método de agrupamento de Tocher, com o propósito de discriminar os tratamentos que apresentaram maior similaridade, e para agrupar os diferentes tipos de manejo, a matriz de distância generalizada de Mahalanobis. O gráfico com base na análise canônica foi gerado e os grupos formados por meio do agrupamento de Tocher. As análises foram realizadas de acordo com Cruz \& Regazzi (1994), utilizando-se o programa Genes (Cruz, 1997).

\section{RESULTADOS E DISCUSSÃO}

Os manejos e usos do solo, no Neossolo, promoveram alterações $(p<0,05)$ na densidade do solo (Ds), volume total de poros (VTP) e na macroporosidade (Ma), quando comparados ao Cerrado (Quadro 3). O efeito do pisoteio das pastagens pelo gado e o uso de máquinas agrícolas nas demais áreas podem ter contribuído para maior densidade do solo nas áreas estudadas, em relação ao Cerrado, a exemplo do verificado por Corsini \& Ferraudo (1999) em áreas com tráfego intenso. Mesmo havendo alteração da densidade do solo em relação ao Cerrado, os valores encontrados foram menores que o índice crítico do crescimento radicular de solos arenosos, $1,75 \mathrm{~kg} \mathrm{dm}^{-3}$ (Medina, 1985; Corsini \& Ferraudo, 1999). Nos primeiros anos de plantio direto, ocorreu aumento na densidade do solo pelo rearranjamento das partículas de solo; no entanto, com a consolidação do sistema, houve aumento nos teores de $\mathrm{C}$ orgânico e, com isso, diminuição na densidade do solo (Machado \& Brum, 1978; Tormena et al., 1998).

A redução no VTP e na Ma em todas as áreas, com relação ao Cerrado, excetuando-se a área sob pastagem nativa (Quadro 3), também está de acordo com as observações de Tormena et al. (1998), que verificaram redução de até $24 \%$ no VTP, quando comparado com áreas que não sofreram ação antrópica. O pisoteio de animais, máquinas agrícolas e manejo inadequado irão acarretar interferências na estrutura do solo, promovendo redução no VTP. A microporosidade não foi influenciada pelo manejo do solo e é considerada baixa neste solo, decorrente do alto teor de areia nele encontrado $\left(920 \mathrm{~g} \mathrm{~kg}^{-1}\right)$.

As áreas sob integração agricultura-pecuária, pastagem e milho em PD apresentaram a mesma resistência mecânica do solo à penetração que a encontrada na área sob Cerrado (Quadro 3), nas mesmas condições de umidade do solo. Esses resultados devem-se, provavelmente, à menor interferência antrópica no solo das áreas de integração agricultura-pecuária e pastagem, além do fato de esse solo possuir estrutura fraca, imprimindo baixa resistência à penetração. Apesar de a área com milho em PD apresentar a mesma resistência mecânica que a área com Cerrado, verifica-se tendência de aumento deste atributo. Provavelmente, o valor da resistência do solo à penetração encontrada na pastagem nativa, aproximadamente $91 \%$ maior que a área com Cerrado, pode ser atribuído ao pisoteio animal nessa área por mais de 20 anos. Entretanto, esses valores de resistência à penetração não são considerados impeditivos ao crescimento e desenvolvimento de plantas, que podem variar de 3 a $5 \mathrm{MPa}$, dependendo do tipo de solo, manejo e uso do solo, culturas, umidade, entre outros (Arshad et al., 1996; Souza \& Alves, 2003).

No Latossolo, verificou-se que os manejos e usos do solo promoveram aumento na Ds e efeito menos pronunciado na Ma em relação ao Cerrado; o VTP e a Mi não diferiram da área de referência (Quadro 3). A Ds aumentou $7 \%$ em relação ao Cerrado, porém os valores obtidos nos diferentes manejos e uso do solo não atingiram valores impeditivos ao crescimento radicular, que se situa em torno de $1,27 \mathrm{~kg} \mathrm{dm}^{-3}$ para solos argilosos (Alvarenga et al., 1996). O VTP não foi influenciado pelos sistemas de uso e manejo do solo ( $p>0,05)$; entretanto, houve tendência de maior VTP nas áreas sob sorgo em PD, Cerrado e pastagem e menor nas áreas sob sistema plantio direto com as culturas do nabo em PD e milheto em PC. Estudo realizado por Corsini \& Ferraudo (1999), em áreas submetidas a cultivo, mostrou diminuição da porosidade do solo e do potencial de crescimento radicular na camada superficial. A área sob milheto em PC teve redução de $38 \%$ nos valores de Ma; nas demais áreas, a redução foi de $29 \%$, comparativamente ao Cerrado. A Ma variou de $0,15 \mathrm{~m}^{3} \mathrm{~m}^{-3}$ na área em que se cultivou nabo em PD a $0,21 \mathrm{~m}^{3} \mathrm{~m}^{-3}$ no Cerrado nativo, tendo-se verificado redução de $29 \%$, o que corrobora dados de Tormena et al. (1998), que observaram redução de até 28 \% nos macroporos em relação a uma área não cultivada. Apesar dessas variações na Ma, os sistemas de uso e manejo do solo não provocaram variações significativas.

No Latossolo Vermelho, a área sob Cerrado nativo apresentou os menores valores de resistência do solo à penetração (Quadro 3) e umidade em torno de $28 \%$. As áreas sob pastagem, milheto em PC e nabo em PD apresentaram os maiores valores de resistência à penetração, provavelmente devido ao pastejo intensivo e pelo fato de o sistema radicular da gramínea ser fasciculado, promovendo aumento na resistência à penetração em razão do contato do cone do penetrômetro com as raízes (Medina, 1985) e em consequência do uso de máquinas agrícolas no nabo em PD. As alterações promovidas no solo pelo tráfego 
Quadro 3. Características físicas nos diferentes sistemas de manejo e uso em um Neossolo Quartzarênico órtico e um Latossolo Vermelho distrófico

\begin{tabular}{|c|c|c|c|c|c|}
\hline Sistema de uso e manejo do solo & Ds & VTP & Ma & Mi & RSP \\
\hline & $\mathrm{kg} \mathrm{dm}^{-3}$ & & $\mathrm{~m}^{3} \mathrm{~m}^{-3}$ & & $\mathrm{MPa}$ \\
\hline & \multicolumn{5}{|c|}{ Neossolo Quartzarênico } \\
\hline Cerrado & $1,42 \mathrm{~b}$ & $0,42 \mathrm{a}$ & $0,34 \mathrm{a}$ & $0,08 \mathrm{a}$ & $1,03 \mathrm{c}$ \\
\hline Pastagem Nativa & $1,56 \mathrm{a}$ & $0,39 \mathrm{ab}$ & $0,30 \mathrm{ab}$ & $0,08 \mathrm{a}$ & $1,96 \mathrm{a}$ \\
\hline Integ. Agri.-Pec. & $1,57 \mathrm{a}$ & $0,35 \mathrm{bc}$ & $0,28 \mathrm{bc}$ & $0,07 \mathrm{a}$ & $1,19 \mathrm{bc}$ \\
\hline Pastagem & $1,57 \mathrm{a}$ & $0,34 \mathrm{c}$ & $0,25 \mathrm{c}$ & $0,07 \mathrm{a}$ & $1,06 \mathrm{c}$ \\
\hline Soja em PD & $1,60 \mathrm{a}$ & $0,35 \mathrm{bc}$ & $0,27 \mathrm{bc}$ & $0,08 \mathrm{a}$ & $1,52 \mathrm{~b}$ \\
\hline \multirow[t]{2}{*}{ Milho em PD } & $1,56 \mathrm{a}$ & $0,36 \mathrm{bc}$ & $0,28 \mathrm{bc}$ & $0,08 \mathrm{a}$ & $1,35 \mathrm{bc}$ \\
\hline & \multicolumn{5}{|c|}{ Latossolo Vermelho } \\
\hline Cerrado & $1,08 \mathrm{~b}$ & $0,56^{\mathrm{ns}}$ & $0,24 \mathrm{a}$ & $0,33^{\mathrm{ns}}$ & $1,32 \mathrm{c}$ \\
\hline Pastagem & $1,13 \mathrm{ab}$ & 0,54 & $0,17 \mathrm{ab}$ & 0,37 & $2,27 \mathrm{a}$ \\
\hline Milheto em PC & $1,16 \mathrm{a}$ & 0,51 & $0,15 \mathrm{~b}$ & 0,36 & $2,21 \mathrm{a}$ \\
\hline Nabo em PD & $1,16 \mathrm{a}$ & 0,51 & $0,17 \mathrm{ab}$ & 0,34 & $2,34 \mathrm{a}$ \\
\hline Sorgo em PD & $1,16 \mathrm{a}$ & 0,57 & $0,17 \mathrm{ab}$ & 0,40 & $1,92 \mathrm{~b}$ \\
\hline
\end{tabular}

PD: plantio direto; PC: preparo convencional. Médias seguidas pela mesma letra na coluna não diferem entre si pelo teste de Tukey $(p<0,05)$. Ds: densidade do solo, VTP: volume total de poros, Ma: macroporosidade, Mi: microporosidade e RSP: resistência do solo à penetração.

durante o processo de plantio, pulverizações e colheita podem ter contribuído para esse aumento da resistência à penetração. Contudo, esses valores de resistência à penetração não são considerados impeditivos ao crescimento radicular, mesmo porque não ocorrem aumentos de Ds do solo que poderiam indicar sua degradação física (Quadro 3).

Os atributos químicos mostraram pequena variação entre as áreas sob diferentes manejos e uso do solo: no entanto, diferiram na maioria das variáveis quando comparados com os do Cerrado (Quadro 4). Nos dois solos, as áreas sob vegetação de Cerrado apresentaram maior $\mathrm{H}+\mathrm{Al}$ e $\mathrm{Al}^{3+}$ e menor concentração de $\mathrm{Ca}, \mathrm{Mg}$ e $\mathrm{P}$ em relação às áreas manejadas, o que está coerente, pois nesta área não houve correção e adubação do solo e se trata de solos originalmente distróficos.

Os valores de $\mathrm{pH}$ não diferiram no Neossolo, mas sim no Latossolo, indicando que a calagem, antes da implantação das culturas, contribuiu para o seu aumento, o que é corroborado com a diminuição do do

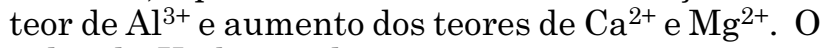
valor de $\mathrm{K}$ observado para a pastagem nativa no Neossolo mostra que a erosão e a lixiviação podem ter contribuído para a perda deste nutriente. $\mathrm{O}$ menor teor de cátions trocáveis no Neossolo em relação ao Latossolo pode ser atribuído à baixa CTC deste solo e às perdas de nutrientes pouco retidos nos sítios de troca, devendo, dessa forma, ser manejados com critérios rigorosos, a fim de atingirem seu máximo potencial produtivo, sem que provoque a sua degradação. No Neossolo, o teor de $\mathrm{P}$ no solo sob pastagem não diferiu dos valores encontrados para o Cerrado e pastagem nativa. Para o Latossolo, o aporte de P pela adubação promoveu aumento desse elemento no tratamento sob milheto em PC e no nabo em PD em relação ao teor encontrado no Cerrado. Tem-se adotado como critério para a adubação fosfatada o teor da fração argila nos solos, devido à alta afinidade de $\mathrm{P}$ com óxidos. Isso tem levado a doses excessivas de $\mathrm{P}$ aplicadas ao solo, o que pode ter contribuído para esse fato.

Para o C orgânico total (COT), verificou-se que os manejos e uso do solo apresentaram influência, com maior concentração no solo sob pastagem cultivada e menor no solo sob pastagem nativa no Neossolo (Quadro 4). Este atributo mostrou-se pouco sensível ao manejo e ao uso do solo, onde somente áreas com grande interferência antrópica e longo tempo de uso mostram diferenças entre si, corroborando outro estudo realizado nessa mesma área (Souza et al., 2006). No entanto, o C da fração leve (CFL) foi severamente alterado pelos manejos, apresentando redução de $50 \%$ em solo de pastagem nativa e de até $71 \%$ em solo sob pastagem, em relação ao Cerrado (Quadro 4). No Latossolo, observou-se que a área sob Cerrado apresentou menor concentração de COT e maior de CFL. Essa maior concentração de CFL deve-se ao não revolvimento do solo, o que favorece a maior proteção da matéria orgânica. A proteção física da matéria orgânica contra a ação microbiana exercida pela estrutura do solo promovida pelas raízes fasciculadas das gramíneas pode explicar a maior concentração de COT nas demais áreas (Balesdent et al., 2000).

O CFLé um importante componente do C orgânico do solo e atua na manutenção da atividade microbiana do solo e na ciclagem de nutrientes, sendo severamente alterado pelo manejo e uso do solo. O CFL representou 21 e $15 \%$ do COT, no Neossolo e Latossolo, respectivamente, sofrendo acentuada redução conforme se intensificou o uso do solo em 
relação ao Cerrado. Essa maior concentração de CFL nas áreas sob o Cerrado, tanto no Neossolo quanto no Latossolo, deve-se à constante entrada de $\mathrm{C}$ via serapilheira e rizodeposição (Souza et al., 2006), além do fato da preservação da estrutura do solo, que contribui, via agregação, para a proteção e manutenção do $\mathrm{C}$ no solo. Verifica-se que os sistemas de manejo do solo, no Neossolo, têm conseguido adicionar quantidades de resíduos suficientes para manter os teores de COT, com exceção da pastagem nativa, que tem promovido perdas nos teores de COT. Já para o Latossolo, o que se constata é que os sistemas de manejo do solo têm promovido maiores adições de resíduos ao solo, pois todos os tratamentos apresentaram maiores teores de COT, além do fato de que, no Latossolo, a proteção física da matéria orgânica é maior do que no Neossolo.

$\mathrm{O}$ C da biomassa microbiana do solo (C-BM) apresentou menor concentração nas áreas de pastagem nativa e na pastagem cultivada, diferindo $(p \leq 0,05)$ das demais áreas no Neossolo (Quadro 5). Pode-se observar que a respiração microbiana $\left(\mathrm{C}-\mathrm{CO}_{2}\right)$ foi menor na pastagem e na área com milho em PD e maior no solo sob Cerrado. O quociente metabólico $\left(q \mathrm{CO}_{2}\right)$ foi maior na pastagem nativa e menor nas demais áreas sob manejo e uso do solo. A relação entre C na biomassa microbiana e C orgânico total (C-BM/COT) foi reduzida nas áreas de pastagem nativa e pastagem cultivada em relação ao Cerrado. Essa relação reflete quanto do $\mathrm{C}$ orgânico está imobilizado na biomassa microbiana e mostra o potencial de reserva desse elemento no solo (Anderson \& Domsch, 1993). Nesse sentido, as áreas sob pastagem nativa e pastagem cultivada apresentaram menores valores de maneira geral, o que indica menor reserva de energia e nutriente imobilizado na biomassa microbiana. $\mathrm{O}$ resultado está coerente com o estado da pastagem, pois a área de pastagem nativa apresentava sinais de degradação do solo e atualmente está em processo de recuperação. Já a pastagem apresentou baixos teores de $\mathrm{C}$ imobilizado na biomassa microbiana, devido à monocultura da pastagem, uma vez que ocorre a seleção de determinados grupos de microrganismos, que são maiores em sistemas com mais de uma cultura.

Estudos sobre manejos do solo devem buscar sistemas que promovam menores $q \mathrm{CO}_{2}$, pois, nesses sistemas, a biomassa microbiana está em equilíbrio, com menores perdas de $\mathrm{CO}_{2}$ pela respiração, e, com isso, maior é a incorporação de $\mathrm{C}$ à biomassa microbiana (Gama-Rodrigues, 1999). No entanto, não se observa isso em todos os manejos e usos do solo, com exceção da pastagem nativa, na qual a população microbiana do solo consome mais $\mathrm{C}$ para manutenção, promovendo, portanto, perda deste elemento, o que já pode ser observado na concentração do COT (Quadro 4).

No Latossolo, todos os manejos e usos do solo alteraram a concentração do C-BM, apresentando reduções de 56,72 e $80 \%$ para área com sorgo em $\mathrm{PD}$, nabo em PD e milheto em PC, respectivamente, em relação ao Cerrado (Quadro 5). Para a respiração microbiana, com exceção da área sob milheto em PC, as demais não diferiram da área de Cerrado, porém a área sob cultivo de nabo em PD apresentou elevado $q \mathrm{CO}_{2}$, demonstrando a perda de $\mathrm{C}$ do solo, comprovada pela concentração de $\mathrm{C}$ retido na biomassa microbiana (Quadro 5). Um dos atributos biológicos mais

\section{Quadro 4. Atributos químicos nos diferentes sistemas de manejo e uso em um Neossolo Quartzarênico} órtico e um Latossolo Vermelho distrófico

\begin{tabular}{|c|c|c|c|c|c|c|c|c|c|}
\hline $\begin{array}{l}\text { Sistemas de uso e } \\
\text { manejo do solo }\end{array}$ & $\mathbf{p H}$ & $\mathbf{H}+\mathbf{A l}$ & $\mathrm{Al}^{3+}$ & $\mathrm{Ca}^{2+}$ & $\mathrm{Mg}^{2+}$ & $\mathbf{K}$ & $\mathbf{P}$ & $\operatorname{COT}^{(1)}$ & CFL $^{(2)}$ \\
\hline & & \multicolumn{4}{|c|}{$\mathrm{cmol}_{\mathrm{c}} \mathrm{dm}^{-3}$} & \multicolumn{2}{|c|}{$-\mathrm{mg} \mathrm{dm}^{-3}-$} & \multicolumn{2}{|c|}{$-\mathrm{g} \mathrm{kg}^{-1} \_$} \\
\hline & \multicolumn{9}{|c|}{ Neossolo Quartzarênico } \\
\hline Cerrado & $4,9^{\mathrm{ns}}$ & $3,8 \mathrm{a}$ & $0,79 \mathrm{a}$ & $0,13 \mathrm{~b}$ & $0,19 \mathrm{c}$ & $9,0 \mathrm{ab}$ & $1,4 \mathrm{~b}$ & $8,8 \mathrm{ab}$ & $1,87 \mathrm{a}$ \\
\hline Pastagem Nativa & 4,7 & $2,4 \mathrm{~b}$ & $0,60 \mathrm{a}$ & $0,20 \mathrm{~b}$ & $0,15 \mathrm{c}$ & $4,4 \mathrm{~b}$ & $1,7 \mathrm{~b}$ & $6,6 \mathrm{~b}$ & $0,70 \mathrm{~b}$ \\
\hline Integ. Agri. -Pec. & 5,4 & $2,6 \mathrm{~b}$ & $0,21 \mathrm{~b}$ & $0,82 \mathrm{a}$ & $0,34 \mathrm{bc}$ & $7,4 \mathrm{ab}$ & $13,0 \mathrm{a}$ & $8,6 \mathrm{ab}$ & $0,87 \mathrm{~b}$ \\
\hline Pastagem & 5,6 & $2,1 \mathrm{~b}$ & $0,19 \mathrm{~b}$ & $0,78 \mathrm{a}$ & $0,42 \mathrm{ab}$ & $12,4 \mathrm{a}$ & $3,2 \mathrm{~b}$ & $10,6 \mathrm{a}$ & $0,69 \mathrm{~b}$ \\
\hline Soja em PD & 5,7 & $1,8 \mathrm{~b}$ & $0,09 \mathrm{~b}$ & $1,06 \mathrm{a}$ & $0,63 \mathrm{a}$ & $12,4 \mathrm{a}$ & $10,2 \mathrm{a}$ & $9,2 \mathrm{ab}$ & $0,65 \mathrm{~b}$ \\
\hline \multirow[t]{2}{*}{ Milho em PD } & 5,8 & $1,7 \mathrm{~b}$ & $0,18 \mathrm{~b}$ & $0,77 \mathrm{a}$ & $0,52 \mathrm{ab}$ & $10,4 \mathrm{ab}$ & $10,5 \mathrm{a}$ & $8,5 \mathrm{ab}$ & $0,671 b$ \\
\hline & \multicolumn{9}{|c|}{ Latossolo Vermelho } \\
\hline Cerrado & $5,04 \mathrm{~b}$ & $5,9 \mathrm{a}$ & $0,81 \mathrm{a}$ & $0,14 \mathrm{~b}$ & $0,20 \mathrm{c}$ & $23,0 \mathrm{c}$ & $0,7 \mathrm{c}$ & $25,5 \mathrm{~b}$ & $3,21 \mathrm{a}$ \\
\hline Pastagem & $5,61 \mathrm{a}$ & $4,9 \mathrm{ab}$ & $0,17 \mathrm{~b}$ & $2,74 \mathrm{a}$ & $0,91 \mathrm{~b}$ & $78,5 \mathrm{abc}$ & $12,0 \mathrm{bc}$ & $34,3 \mathrm{a}$ & $1,51 \mathrm{~b}$ \\
\hline Milheto em PC & $5,88 \mathrm{a}$ & $4,5 \mathrm{ab}$ & $0,15 \mathrm{~b}$ & $3,11 \mathrm{a}$ & $1,05 \mathrm{~b}$ & $120,7 \mathrm{a}$ & $29,6 \mathrm{a}$ & $34,2 \mathrm{a}$ & $1,08 \mathrm{~b}$ \\
\hline Nabo em PD & $5,86 \mathrm{a}$ & $5,0 \mathrm{ab}$ & $0,21 \mathrm{~b}$ & $2,54 \mathrm{a}$ & $1,18 \mathrm{ab}$ & $98,1 \mathrm{ab}$ & $16,5 \mathrm{ab}$ & $31,1 \mathrm{ab}$ & $1,08 \mathrm{~b}$ \\
\hline Sorgo em PD & $5,83 \mathrm{a}$ & $4,2 \mathrm{~b}$ & $0,13 \mathrm{~b}$ & $2,71 \mathrm{a}$ & $1,63 \mathrm{a}$ & $52,1 \mathrm{bc}$ & $13,9 \mathrm{bc}$ & $30,6 \mathrm{ab}$ & $1,53 \mathrm{~b}$ \\
\hline
\end{tabular}

(1) COT: C orgânico total. ${ }^{(2)} \mathrm{CFL}$ : C da fração leve. PD: plantio direto; PC: preparo convencional. Médias seguidas pela mesma letra na coluna não diferem entre si pelo teste de Tukey $(p<0,05)$. 
Quadro 5. Características biológicas em diferentes sistemas de manejo e uso em um Neossolo Quartzarênico órtico e um Latossolo Vermelho distrófico

\begin{tabular}{|c|c|c|c|c|c|c|c|c|}
\hline \multirow{2}{*}{$\begin{array}{l}\text { Sistemas de uso } \\
\text { e manejo do solo }\end{array}$} & \multirow{2}{*}{ C-BM } & \multirow{2}{*}{ Respiração } & \multirow{2}{*}{$\mathrm{qCO}_{2}$} & \multirow{2}{*}{$\begin{array}{c}\mathrm{C}- \\
\mathrm{BM} / \mathrm{COT}\end{array}$} & \multirow{2}{*}{ Urease } & \multirow{2}{*}{$\begin{array}{l}\text { Fosfatase } \\
\text { ácida }\end{array}$} & \multicolumn{2}{|c|}{ FMAs } \\
\hline & & & & & & & Esporos & Colonização \\
\hline & $\mu \mathrm{g} \mathrm{g}$ solo $^{-1}$ & $\begin{array}{l}\mathrm{mg} \mathrm{h}^{-1} \\
\mathrm{C}-\mathrm{CO}_{2}\end{array}$ & $\begin{array}{l}\mathrm{mg} \mathrm{C}-\mathrm{CO} \mu \mathrm{g} \\
\mathrm{C}-\mathrm{BM} \mathrm{h}^{-1}\end{array}$ & $\%$ & $\begin{array}{l}\mu \mathrm{g} \mathrm{N}-\mathrm{NH}_{4}^{+} \\
\mathrm{g} \mathrm{solo}^{-1} \mathrm{~h}^{-1}\end{array}$ & $\begin{array}{c}\mu \mathrm{g} \mathrm{PNF} \\
\mathrm{g} \mathrm{solo}^{-1} \mathrm{~h}^{-1}\end{array}$ & $\mathrm{n}(50 \mathrm{ml} \text { solo })^{-1}$ & $\%$ \\
\hline & & & & Neossolo Q & uartzarênico & & & \\
\hline Cerrado & $275 \mathrm{a}$ & $5,9 \mathrm{a}$ & 0,022 & 3,1 & $4,2 \mathrm{bc}$ & $137 \mathrm{ab}$ & $428 \mathrm{~b}$ & $37 \mathrm{~b}$ \\
\hline Pastagem Nativa & $89 \mathrm{c}$ & $2,9 \mathrm{ab}$ & 0,033 & 1,3 & $4,0 \mathrm{c}$ & $102 \mathrm{c}$ & $884 \mathrm{a}$ & $79 \mathrm{a}$ \\
\hline Integ. Agri. -Pec. & $332 \mathrm{a}$ & $3,2 \mathrm{ab}$ & 0,010 & 3,9 & $7,4 \mathrm{~b}$ & $140 \mathrm{a}$ & $907 \mathrm{a}$ & $43 \mathrm{~b}$ \\
\hline Pastagem & $197 \mathrm{~b}$ & $1,1 \mathrm{~b}$ & 0,005 & 1,9 & $6,2 \mathrm{bc}$ & $136 \mathrm{ab}$ & 910 a & $51 \mathrm{~b}$ \\
\hline Soja em PD & $321 \mathrm{a}$ & $4,0 \mathrm{ab}$ & 0,012 & 3,5 & $10,9 \mathrm{a}$ & $140 \mathrm{a}$ & $941 \mathrm{a}$ & $40 \mathrm{~b}$ \\
\hline \multirow[t]{2}{*}{ Milho em PD } & $413 \mathrm{a}$ & $2,3 \mathrm{~b}$ & 0,005 & 4,9 & $3,7 \mathrm{c}$ & $125 \mathrm{~b}$ & $940 \mathrm{a}$ & $40 \mathrm{~b}$ \\
\hline & \multicolumn{8}{|c|}{ Latossolo Vermelho } \\
\hline Cerrado & $541 \mathrm{a}$ & 7,9 a & 0,015 & 2 & $22,5 \mathrm{a}$ & $144^{\mathrm{ns}}$ & $373^{\mathrm{ns}}$ & $35^{\mathrm{ns}}$ \\
\hline Pastagem & $334 \mathrm{~b}$ & $5,6 \mathrm{ab}$ & 0,017 & 1 & $7,7 \mathrm{~b}$ & 141 & 587 & 41 \\
\hline Milheto em PC & $106 \mathrm{c}$ & $2,6 \mathrm{~b}$ & 0,024 & $<1$ & $5,4 \mathrm{~b}$ & 147 & 734 & 34 \\
\hline Nabo em PD & $149 \mathrm{c}$ & $7,8 \mathrm{a}$ & 0,052 & $<1$ & $3,8 \mathrm{~b}$ & 143 & 532 & 38 \\
\hline Sorgo em PD & $236 \mathrm{bc}$ & $4,8 \mathrm{ab}$ & 0,021 & $<1$ & $6,4 \mathrm{~b}$ & 143 & 704 & 48 \\
\hline
\end{tabular}

PD: plantio direto; PC: preparo convencional. Médias seguidas pela mesma letra não diferem entre si, na coluna, pelo teste de Tukey $(\mathrm{p}<0,05)$.

importantes é a biomassa microbiana do solo, que é a parte viva da matéria orgânica do solo, pois atua como agente da transformação bioquímica dos resíduos adicionados ao solo e compostos orgânicos e como reservatório de nutrientes (Moreira \& Siqueira, 2002). É utilizada como indicador biológico da qualidade do solo. Estudos conduzidos em solos de Cerrado demonstram que a adoção do sistema de plantio direto contribuiu para o aumento da biomassa microbiana em relação ao plantio convencional (D'Andréa et al., 2002). Neste estudo, no Latossolo, observou-se que, em todos os manejos e usos do solo, a C-BM e a relação entre o C microbiano e o C orgânico total foram reduzidas, em relação ao Cerrado.

As atividades da urease e da fosfatase ácida no Neossolo foram alteradas pelos manejos e usos do solo (Quadro 5). A urease foi mais elevada na área sob soja em PD em relação às demais áreas estudadas, e a atividade da fosfatase ácida foi menor na área sob pastagem nativa, sendo diferente das demais áreas estudadas $(p \leq 0,05)$. No Latossolo, todos os manejos e usos do solo promoveram redução na atividade da urease em relação ao Cerrado; contudo, não foram observadas diferenças significativas entre eles. Resultado semelhante foi encontrado para a atividade da fosfatase ácida.

O sistema de uso do solo tem grande influência sobre a atividade enzimática do solo (Doran \& Parkin, 1994). Estudo desenvolvido em Latossolo Vermelho mostrou que a atividade da urease foi reduzida em 33 e $72 \%$ em solos sob pastagens (10 anos) e algodão, respectivamente, quando comparado com solos sob mata (Marchiori-Júnior, 1998); resultados semelhantes foram encontrados em outros solos cultivados com trigo e milho nos EUA (Hector \& Robert, 1989; Riffaldi et al., 1994) e em solos da Amazônia (Fernandes, 1999). Doran (1987) e Dick (1994) verificaram aumento da atividade enzimática na superfície do solo em sistema de plantio direto comparado com plantio convencional, devido ao menor distúrbio no solo neste sistema. Esses resultados divergem do encontrado neste estudo para o Latossolo, o que pode ser explicado pela recente adoção do sistema de plantio direto nas áreas estudadas. Já para o Neossolo, os resultados encontrados pelos autores supracitados corroboram este estudo, porém não há estudos dessa natureza em solos arenosos, principalmente em solos de Cerrado.

No Neossolo, foi observado menor número de esporos de fungos micorrízicos arbusculares (FMAs) na área de Cerrado e maior colonização micorrízica das raízes na área de pastagem nativa. Esse fato não foi observado no Latossolo, não havendo diferença entre as áreas estudadas para número de esporos de FMA e colonização micorrízica. Os FMAs são um dos principais componentes da microbiota do solo e mais comumente encontrados nos biomas tropicais, ocupando importante nicho ecológico nos ecossistemas, sendo influenciados pelas práticas de manejo e uso, que podem reduzir a incidência de algumas espécies de FMA, ocasionando a perda da biodiversidade (Moreira \& Siqueira, 2006). Isso adquire relevância no bioma Cerrado devido à intensidade de uso do solo, fragilidade e grande diversidade edáfica e climática, além do avanço da agricultura, que vem incorporando cada vez mais áreas de Cerrado nativo ao processo de produção de grãos, carne e energia. Neste estudo, não foi encontrado efeito dos manejos e uso do solo na população e na colonização micorrízica.

$\mathrm{Na}$ análise canônica dos atributos físicos, químicos e biológicos do solo sob diferentes manejos e usos do 
solo para o Neossolo, a primeira e a segunda variável canônica corresponderam a 48,6 e 37,3 \% da variação total, respectivamente. Isso representa $85,9 \% \mathrm{da}$ variação total, o que, de acordo com Cruz \& Regazzi (1994), é satisfatório para avaliação por meio da dispersão gráfica dos escores em relação às primeira e segunda variáveis canônicas. Além da dispersão gráfica, o método de agrupamento de Tocher foi utilizado e evidenciou a formação de três grupos: dois formados por um único manejo e uso (o primeiro pelo Cerrado e o segundo pela pastagem nativa em processo de reabilitação) e um terceiro formado por soja em $\mathrm{PD}$, milho em PD, pastagem e integração agriculturapecuária (Figura 1), demonstrando que os manejos e uso deste solo com o plantio direto, nas áreas de soja em PD e milho em PD, da integração agriculturapecuária e pastagem apresentaram comportamento similar quando considerado o conjunto das varáveis em estudo, fato também determinado nos atributos avaliados pelo teste de médias. No entanto, com relação à área de Cerrado, esses manejos e uso do solo provocaram reduções em vários atributos estudados, o que pode levar à degradação deste solo com o tempo, como já observado em várias áreas em torno do experimento deste estudo. Isso é bem evidente na área de pastagem nativa em processo de reabilitação, que se apresenta afastada das demais áreas estudadas.

As variáveis de menor importância, por apresentarem maior coeficiente de ponderação nas últimas variáveis canônicas, ou seja, aquelas que retêm pequena parte da variação total disponível, são volume total de poros, microporos, macroporos e densidade do solo. Isso mostra que os atributos mencionados pouco contribuem para discriminar os tipos de manejo e uso do solo, corroborando outros estudos que evidenciam maior discriminação pelos atributos biológicos (Maluche-Baretta et al., 2006).

Para o Latossolo, as duas primeiras variáveis canônicas explicam, respectivamente, 90,3 e 7,8 \%, o que representa $98,1 \%$ da variância total disponível nas variáveis em estudo, também possibilitando o estudo por meio da dispersão gráfica dessas duas variáveis num espaço bidimensional. As áreas foram classificadas em dois grupos, sendo o primeiro composto pela área de Cerrado e pastagem e o segundo pelas áreas de sorgo em PD, milheto em $\mathrm{PC}$ e nabo em PD (Figura 1). Portanto, a área sob pastagem em Latossolo foi a mais próxima da referência (Cerrado); nas demais áreas, o manejo e o uso do solo devem ser alterados para que se proporcionem melhorias nos atributos estudados. Isso pode ser feito mantendo-se a área sempre com vegetação de cobertura, o que proporciona aumento da adição de resíduos ao solo e, consequentemente, maiores teores de matéria orgânica do solo, contribuindo, assim, para a melhoria de todos os atributos do solo (Bayer, 1996). As variáveis que apresentaram menor discriminação dos manejos e uso do solo, por apresentarem maior coeficiente de ponderação nas últimas variáveis canônicas, foram: microporos, macroporos, densidade do solo, volume total de poros e teor de P. Evidenciou-se, assim como encontrado no Neossolo, na condição deste estudo, que os atributos físicos pouco contribuíram na deteç̧ão de diferenças entre os tipos de manejo e uso do solo.

\section{CONCLUSÕES}

1. Os manejos e uso do solo alteram os atributos físicos, químicos e biológicos nos dois solos.

2. Os atributos físicos avaliados, agrupados, apresentaram as menores contribuições na discriminação dos manejos e usos dos solos.

3. No Neossolo Quartzarênico, nenhum dos sistemas e uso do solo foi agrupado com a área de referência; já no Latossolo Vermelho a área sob pastagem manteve-se mais próxima da área de Cerrado.
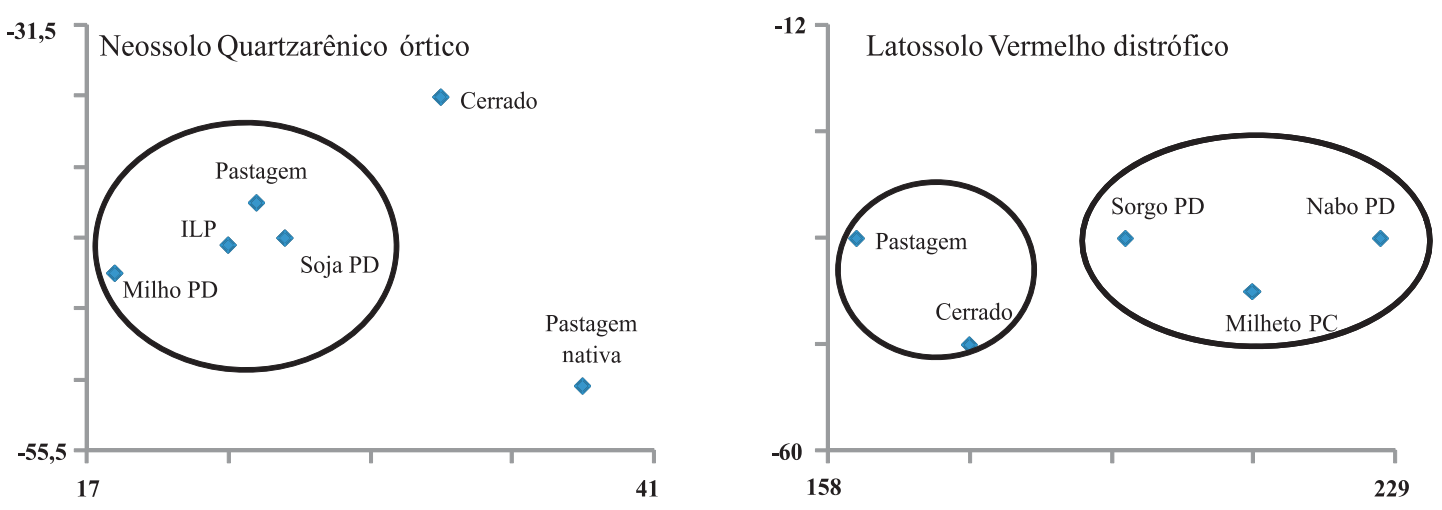

AUTOVETORES

Figura 1. Dispersão dos diferentes sistemas de uso e manejo e agrupamento pelo método de Tocher das duas primeiras variáveis canônicas no Neossolo Quartzarênico órtico e no Latossolo Vermelho distrófico. ILP: integração lavoura-pecuária; PD: plantio direto; PC: preparo convencional. 


\section{AGRADECIMENTOS}

Aos produtores rurais Milton Fries e Eduardo Peixoto, por cederem suas propriedades e pelo apoio logístico para realização deste estudo. Ao professor Ibanor Anghinoni pelas valiosas sugestões.

\section{LITERATURA CITADA}

ALEF, K. \& NANNIPIERI, P., eds. Methods in applied soil microbiology and biochemistry. London, Academic Press, 1995. $576 \mathrm{p}$

ALVARENGA, R.C.; COSTA, L.M.; MOURA FILHO, W. \& REGAZZI, A.J. Crescimento de raízes de leguminosas em camadas de solo compactadas artificialmente. R. Bras. Ci. Solo, 20:319-326, 1996.

ANDERSON, J.P.E. \& DOMSCH, K.H. The metabolic quotient $\left(q \mathrm{CO}_{2}\right)$ as a specific activity parameter to asses the effects of environmental conditions, such as $\mathrm{pH}$, on the microbial biomass of forest soils. Soil Biol. Biochem., 25:393-395, 1993.

ARSHAD, M.A.; LOWERY, B. \& GROSSMAN, B. Physical tests for monitoring soil quality. In: DORAN, J.W. \& JONES, A.J., eds. Methods for assessing soil quality. Madison, Soil Science Society of America, 1996. p.123141. (SSSA Special Publication, 49)

BALESDENT, J.; CHENU, C. \& BALABANE, M. Relationship of soil organic matter dynamics to physical protection and tillage. Soil Till. Res., 53:215-230, 2000.

BAYER, C. Dinâmica da matéria orgânica em sistemas de manejo de solos. Porto Alegre, Universidade Federal do Rio Grande do Sul, 1996. 240p. (Tese de Doutorado)

BLAKE, G.R. \& HARTAGE, K.H. Bulk density. In: KLUTE, A., ed. Methods of soil analysis: Physical and mineralogical methods. Madison, America Society of Agronomy, 1986. p.363-375.

BROOKES, P.C. The use of microbial parameters in monitoring soil pollution by heavy metals. Biol. Fert. Soils, 19:269-279, 1995.

CORSINI, P.C. \& FERRAUDO, A.S. Efeitos de sistemas de cultivo na densidade e macroporosidade do solo e no desenvolvimento radicular do milho em Latossolo Roxo. Pesq. Agropec. Bras., 34:289-298, 1999.

CRUZ, C.D. Programa GENES - Aplicativo computacional em genética e estatística. Viçosa, MG, Universidade Federal de Viçosa, 1997. 442p.

CRUZ, C.D. \& REGAZZI, A.J. Modelos biométricos aplicados ao melhoramento genético. Viçosa, MG, Universidade Federal de Viçosa, 1994. 394p.

CRUZ-CASTILHO, J.G.; GANESHANANDAM, S.; MACKAY, B.R.; LAWES, G.S.; LAWOKO, C.R.O.O. \& WOOLLEY, D.J. Applications of canonical discriminat analysis in horticultural research. Hortic. Sci., 29:1115-1119, 1994.
D'ANDRÉA, A.F.; SILVA, M.L.N.; CURI, N.; SIQUEIRA, J.O. \& CARNEIRO, M.A.C. Atributos biológicos indicadores da qualidade do solo em sistemas de manejo na região do Cerrado no sul do Estado de Goiás. R. Bras. Ci. Solo, 26:913-923, 2002.

DICK, R.P. Soil enzyme activities as indicators of soil quality. In: DORAN, J.W.; COLEMAN, D.C.; BEZDICEK, D.F. \& STUWART, B.A., eds. Defining soil quality for sustainable environment. Madison, Soil Science Society of America, 1994. p.107-124.

DICK, R.P.; BREAKWELL, D.P. \& TURCO, R.F. Soil enzyme activities and biodiversity measurements as integrative microbiological indicators. In: DORAN, J.W. \& JONES, A.J., eds. Methods for assessing soil quality. Madison, Soil Science Society of America, 1996. p.247-272.

DORAN, J.W. \& PARKIN, T.B. Defining and assessing soil quality. In: DORAN, J.W.; CELEMAN, D.C.; BEZDICEK, D.F. \& STEWART, B.A., eds. Defining soil quality for sustainable environment. Madison, Soil Science Society of America, 1994. p.3-21.

DORAN, J.W. Microbial biomass and mineralizable nitrogen distributions in notillage and plowed soils. Biol. Fert. Soils, 5:68-75, 1987.

EMPRESA BRASILEIRA DE PESQUISA AGROPECUÁRIA EMBRAPA. Serviço Nacional de Levantamento e Conservação de Solos. Manual de métodos de análise de solos. 2.ed. Rio de Janeiro, 1997. 212p.

FERNANDES, S.A.P. Propriedades do solo na conversão de floresta em pastagem fertilizada e não fertilizada com fósforo na Amazônia (Rondônia). Piracicaba, Escola Superior de Agricultura Luiz de Queiroz, 1999. 131p. (Tese de Doutorado)

GAMA-RODRIGUES, E.F. Biomassa microbiana e ciclagem de nutrientes. In: SANTOS, G.A. \& CAMARGO, F.A.O., eds. Fundamentos da matéria orgânica: Ecossistemas tropicais e subtropicais. Porto Alegre, Gênesis, 1999. p.227-244.

GERDEMANN, J.W. \& NICOLSON, T.H. Spores of mycorrhizal Endogone species extracted from soil by wet sieving and decanting. Trans. Br. Mycol. Soc., 46:235-244, 1963.

GIOVANNETTI, M. \& MOSSE, B. An evaluation of techniques to measure vesicular-arbuscular mycorrhizal infection in roots. New Phytol., 84:484-500, 1980.

KLUTHCOUSKI, J.; STONE, L.F. \& AIDAR, H. Integração lavoura-pecuária. Santo Antônio de Goiás, Embrapa Arroz e Feijão, 2003. 570p.

HECTOR, J.B. \& ROBERT, L.W. Soil urease activity in management systems. Winter wheat residue. Soil Sci. Soc. Am. J., 53:1455-1458, 1989.

MARCHIORI-JÚNIOR, M. Carbono, nitrogênio, biomassa microbiana e atividade enzimática num solo sob mata natural ou cultivado com pastagem ou algodoeiro. Jaboticabal, Universidade Estadual de São Paulo, 1998. 89p. (Tese de Mestrado) 
MACHADO, J.A. \& BRUM, A.C.R. Efeito de sistemas de cultivo em algumas propriedades físicas do solo. R. Bras. Ci. Solo, 2:81-84, 1978.

MALUCHE-BARRETA, C.R.D.; AMARANTE, C.V.T. \& KLAUBERG-FILHO, O. Análise multivariada de atributos do solo em sistemas convencional e orgânico de produção de maçãs. Pesq. Agropec. Bras., 41:1531-1539, 2006.

MEDINA, B.F. Influência de dois métodos de preparo de área na compactação de um Latossolo Amarelo. R. Bras. Ci. Solo, 9:67-71, 1985.

MOREIRA, F.M.S. \& SIQUEIRA, J.O. Microbiologia e bioquímica do solo. Lavras, Universidade Federal de Lavras, 2006. 626p.

NICOLODI, M. Desafios à caracterização de solo fértil em química do solo. In: REUNIÃO SUL-BRASILEIRA DE CIÊNCIA DO SOLO, 6., Passo Fundo, 2006. Anais. Passo Fundo, Embrapa, 2006. CD-ROM.

RIFFALDI, R.; SAVOZZI, A.; LEVI-MINZI, R. \& MENCHETTI, F. Chemical characteristics of soil after 40 years of continuous maize cultivation. Agric. Ecossyst. Environ., 49:239-245, 1994.

ROSCOE, R. \& MACHADO, P.L.O.A. Fracionamento físico do solo em estudos da matéria orgânica. Dourados, Embrapa Agropecuária Oeste; Rio de Janeiro, Embrapa Solos, 2002. 86p.
SILVA, V.R.; REINERT, D.J. \& REICHERT, J.M. Densidade do solo, atributos químicos e sistema radicular do milho afetados pelo pastejo e manejo do solo. R. Bras. Ci. Solo, 24:191-199, 2000

SOUZA, Z.M. \& ALVES, M.C. Movimento de água e resistência à penetração em um Latossolo Vermelho distrófico de Cerrado, sob diferentes usos e manejos. R. Bras. Eng. Agric. Amb., 7:18-23, 2003.

SOUZA, E.D.; CARNEIRO, M.A.C.; PAULINO, H.B.; SILVA, C.A. \& BUZETTI, S. Alterações nas frações do $\mathrm{C}$ em um Neossolo Quartzarênico submetido a diferentes sistemas de uso do solo. Acta Sci. Agron., 28:323-329, 2006.

STOLF, R. Teoria e teste experimental de fórmulas de transformação de dados de penetrômetro de impacto em resistência do solo. R. Bras. Ci. Solo, 15:229-235, 1991.

TABATABAI, M.A. \& BREMNER, J.M. Assay of urease activity in soil. Soil Biol. Bioci., 4:479-487, 1972.

TORMENA, C.A.; ROLOFF, G. \& SÁ, J.C.M. Propriedades físicas do solo sob plantio direto influenciadas por calagem, preparo inicial e tráfego. R. Bras. Ci. Solo, 22:301-309, 1998.

VANCE, E.D.; BROOKES, P.C. \& JENKINSON, D.S. An extraction method for measuring soil microbial biomass C. Soil Biol. Biochem., 19:703-707, 1987. 